\title{
Association of serum osteoprotegerin with vascular calcification in patients with type 2 diabetes
}

Atsushi Aoki, Miho Murata, Tomoko Asano, Aki Ikoma, Masami Sasaki, Tomoyuki Saito, Taeko Otani, Sachimi Jinbo, Nahoko Ikeda, Masanobu Kawakami and San-e Ishikawa*

\begin{abstract}
Background: Osteoprotegerin is a member of the tumor necrosis factor-related family and inhibits RANK stimulation of osteoclast formation as a soluble decoy receptor. The goal of this study was to determine the relationship of serum osteoprotegerin with vascular calcification in patients with type 2 diabetes.

Methods: The subjects were 124 patients with type 2 diabetes mellitus, including 88 males and 36 females with a mean $( \pm$ SD) age of $65.6 \pm 8.2$ years old. Serum levels of osteoprotegerin, osteocalcin, fibroblast growth factor 23 (FGF23), 25-hydroxyvitamin D3 and adiponectin were measured by ELISA. Vascular calcification in the cervical artery was examined by ultrasound sonography. The subjects were divided into 4 quartiles depending on serum osteoprotegerin levels.

Results: Vascular calcification was significantly higher in the 4th quartile and significantly lower in the 1st quartile of serum osteoprotegerin levels, compared to other quartiles. There were no differences in serum osteoprotegerin and vascular calcification among patients with different stages of diabetic nephropathy, but serum FGF23 levels were elevated in those with stage 4 diabetic nephropathy. Simple regression analysis showed that serum osteoprotegerin levels had significant positive correlations with age, systolic blood pressure and serum adiponectin levels, and significant negative correlations with BMI and serum 25-hydroxyvitamin D3.
\end{abstract}

Conclusions: These findings suggest that elevated serum osteoprotegerin may be involved in vascular calcification independently of progression of diabetic nephropathy in patients with type 2 diabetes.

Keywords: Osteoprotegerin, Vascular calcification, Atherosclerosis, Type 2 diabetes mellitus

\section{Background}

Atherosclerosis, macroangiopathy and microangiopathy are major prognostic factors in diabetes. Vascular endothelial impairment is the initial pathological change and is profoundly involved in development of atherosclerosis [1-4]. Progression of diabetic nephropathy, including microalbuminuria, is a risk factor for atherosclerosis in type 2 diabetes mellitus [5,6] and diabetic patients with advanced nephropathy (particularly those on dialysis with end-stage kidney disease) often have vascular calcification [7-10]. However, the duration of diabetes mellitus is not closely related to the extent of vascular

\footnotetext{
* Correspondence: saneiskw@jichi.ac.jp

Department of Medicine, Jichi Medical University Saitama Medical Center,

1-847 Amanuma Omiya-ku Saitama, Saitama, Japan
}

calcification, and this condition may be more strongly related to biochemical changes.

The RANK/RANKL interaction induces osteoclast formation in vascular smooth muscle cells such as those in bone [11]. Osteoprotegerin, a member of the tumor necrosis factor (TNF)-related family [12], binds to RANKL as a soluble decoy receptor, and consequently inhibits RANK stimulation of osteoclast formation [13]. This suggests that interactions among RANK, RANKL and osteoprotegerin influence osteoclastogenesis and vascular calcification. Therefore, in the present study, we examined the relationship of osteoprotegerin with vascular calcification in patients with type 2 diabetes without advanced nephropathy. 


\section{Methods}

\section{Subjects}

A total of 124 patients with type 2 diabetes mellitus at the outpatient clinic of Jichi Medical University Saitama Medical Center were enrolled in the study between March 2006 and October 2011. The subjects included 88 males and 36 females, and had a mean ( \pm SD) age of $65.6 \pm 8.2$ years old (range: 44 to 82 years old). Type 2 diabetes was diagnosed using Japan Diabetes Society criteria. The mean hemoglobin A1c (HbA1c: NGSP) was $7.7 \pm 1.4 \%$ and the duration of diabetes mellitus was $14.7 \pm 8.2$ years. Of the 124 subjects, 65 had hypertension, 74 had dyslipidemia, 35 were obese, 40 were current smokers, 46 had diabetic retinopathy, 64 had diabetic nephropathy, and 56 had diabetic neuropathy. Patients with end-stage kidney diseases, use of nitroglycerin as maintenance medication, infectious disease, malignancy, and a history of intrapelvic surgery were excluded from the study.

Blood samples were collected from subjects in the sitting position at a visit to the outpatient clinic after an overnight fast. HbA1c (NGSP), serum total cholesterol, high-density lipoprotein cholesterol, low-density lipoprotein cholesterol, triglyceride, calcium, phosphorus, creatinine, serum osteoprotegerin, osteocalcin, fibroblast growth factor (FGF) 23, 25-hydroxyvitamin D3, and adiponectin were measured in these samples. Urine samples were collected to determine urinary excretion of albumin. Ultrasound sonography of the cervical carotid artery and endothelial function tests of flow-mediated dilatation (FMD) and nitroglycerine-mediated dilatation (NMD) were also performed. The study was approved by the ethical committee of Jichi Medical University for human studies. Informed consent was obtained from all subjects.

Regarding risk factors for atherosclerosis, hypertension was defined as systolic blood pressure $>140 \mathrm{mmHg}$, diastolic blood pressure $>90 \mathrm{mmHg}$, or a history of administration of antihypertensive agents; dyslipidemia as a total cholesterol level $>220 \mathrm{mg} / \mathrm{dl}$, high-density lipoprotein cholesterol level $<40 \mathrm{mg} / \mathrm{dl}$, and triglyceride level $>150 \mathrm{mg} / \mathrm{dl}$, or a history of administration of statins or fibrates; obesity as BMI > 25 (Japanese patients); and a current smoker as a subject who had smoked more than one cigarette per day within the last 3 months.

For progression of nephropathy, the subjects were divided into stages 1-5 based on the classification of diabetic nephropathy by the Research Committee of the Japanese Ministry of Health, Labor, and Welfare for Disorders of Diabetes Mellitus.

\section{Measurements}

Blood samples were collected into tubes and centrifuged at $3,000 \mathrm{rpm}$ at $4^{\circ} \mathrm{C}$ for $15 \mathrm{~min}$. The supernatants were decanted and frozen at $-80^{\circ} \mathrm{C}$ until assayed. HbA1c was measured by HPLC using an $\mathrm{ADAMS}^{\mathrm{TM}}$ A1c HA-
8160 instrument (Arkray, Kyoto, Japan). The value for HbA1c (\%) is estimated as a National Glycohemoglobin Standardization Program (NGSP) equivalent value (\%), calculated by the formula HbA1c (\%) = HbA1c (Japan Diabetes Society, JDS) $(\%)+0.4 \%$ [14]. ELISA kits were used to measure the serum levels of osteoprotegerin (Bio Vendor, Modrice, Czech Republic), osteocalcin (Biomedical Technologies Inc., Stoughton, MA, USA), FGF23 (Kainos, Tokyo, Japan), 25-hydroxyvitamin D3 (Immundiagnostik AG., Bensheim, Germany), and adiponectin (Otsuka Pharmaceutical Co., Tokyo, Japan). The minimal levels of detection and interassay and intraassay coefficients of variation were $0.2 \mathrm{pg} / \mathrm{ml}, 5.8 \%$ and $3.5 \%$, respectively, for osteoprotegerin; $0.5 \mathrm{ng} / \mathrm{ml}, 10.5 \%$ and $7.0 \%$, respectively, for osteocalcin; $3 \mathrm{pg} / \mathrm{ml}, 2.6 \%$ and $2.8 \%$, respectively, for FGF23; $12 \mathrm{nmol} / \mathrm{l}, 7.0 \%$ and 7.0\%, respectively, for 25 hydroxyvitamin D3; and $0.375 \mu \mathrm{g} / \mathrm{ml},<10 \%$ and $<10 \%$, respectively, for adiponectin. Urinary excretion of albumin was determined by a latex agglutination immunoassay (Eiken, Tokyo). Renal function was calculated as the estimated glomerular filtration rate (eGFR) using the Modification of Diet in Renal Disease equation (MDRD) revised for Japanese subjects by the Japan Society of Nephrology.

\section{Flow-mediated dilatation (FMD)}

Endothelial function was evaluated by FMD, which indicates an arterial response to reactive hyperemia causing endothelial-dependent dilatation $[15,16]$. FMD of the right brachial artery was determined by one investigator (AA) between 16:00 and 18:00 hours after a 15-minute rest, using a 12-MHz ultrasound instrument (UNEXEF18G, UNEX Corp., Nagoya, Japan), as previously described [17]. The brachial artery was imaged in the longitudinal section just above the antecubital fossa and internal diameters from the anterior to posterior intimal interfaces were measured at end-diastole using B-mode imaging as baseline. A pneumatic cuff was inflated on the forearm at a pressure of more than $50 \mathrm{mmHg}$ higher than systolic blood pressure for $5 \mathrm{~min}$. The intravascular blood flow velocities and vessel diameter were measured from 20 to $120 \mathrm{~s}$ after cuff deflation in the same manner as that as baseline. FMD was calculated as the $\%$ increase in vessel diameter following reactive hyperemia: (maximum diameter following reactive hyperemia-baseline diameter)/baseline diameter $\times 100$. At $15 \mathrm{~min}$ after the FMD measurement, NMD (endothelium-independent dilatation) was measured following administration of sublingual nitroglycerin 0.3 mg-spray. The maximum vessel diameter produced by nitroglycerin was measured $4 \mathrm{~min}$ after administration and NMD was calculated.

\section{Carotid artery sonogram}

A carotid artery sonogram for determination of intimamedia thickness (IMT) and arterial wall calcification was 
performed according to the standard method for ultrasound evaluation of carotid artery lesions [18]. Briefly, measurements of IMT in bilateral carotid arteries were obtained in each subject using a 7.5-MHz ultrasound instrument (Prosound SSD-4000SV, Hitachi Aloka Medical, Tokyo, Japan). The IMT was defined as the distance between the leading edge of the lumen-intima echo and the leading edge of the media-adventitia echo. The mean IMT was obtained from measurements performed on the right and left common carotid artery, excluding the bulbus, as an average of 3 points after measurement of IMT at the point of max IMT and two points on both sides (each 1 $\mathrm{cm}$ distant from the point of max IMT). Arterial calcification was determined at the same points by evaluating the medial calcification (Monckeberg's arteriosclerosis) and intimal calcification (atherosclerosis).

\section{Statistical analysis}

Data are expressed as mean \pm SEM. Values were analyzed by Student t-test and one-way analysis of variance (ANOVA) to compare differences between the groups. Corresponding data were analyzed by Student paired t-test. Categorical data were analyzed by a chi-square test for independence. For regression analysis, log transformation was used to normalize the distribution of serum levels of osteoprotegerin, FGF23, 25-hydroxyvitamin D3, and adiponectin. Simple linear regression analysis was performed to calculate correlation coefficients. All calculations were performed using SPSS $^{\circledR}$ Statistics 18.0 (Japan IBM., Tokyo, Japan) and a two-tailed p value $<0.05$ was considered to be statistically significant.

\section{Results}

The subjects were divided into quartiles using levels of osteoprotegerin, osteocalcin, FGF23, and 25-hydroxyvitamin D3, and the presence or absence of cervical arterial calcification was evaluated in each quartile (Table 1). Based on the serum osteoprotegerin levels, significantly greater vascular calcification was present in subjects in the 4th quartile and significantly less vascular calcification was present in those in the 1st quartile compared to other quartiles (Table 1). The reverse result was found for the absence of calcification (Figure 1). The quartiles based on serum osteocalcin, FGF23 and 25hydroxyvitamin D3 levels did not show any relationship with vascular calcification.

Clinical and laboratory data for the quartiles based on serum osteoprotegerin levels are shown in Table 2. Age and serum adiponectin levels increased with higher serum osteoprotegerin levels $(\mathrm{P}=0.001$ and $\mathrm{P}=0.002$, respectively, in trend tests), and serum 25-hydroxyvitamin D3 levels were significantly lower in the 4 th quartile $(\mathrm{P}=0.002)$.

Vascular calcification and other parameters in the subjects based on clinical stages of diabetic nephropathy, a microvascular angiopathy, are shown in Table 3. Serum creatinine and albuminuria increased and eGFR decreased with progression of nephropathy. Serum FGF23 was elevated in subjects with stage 4 nephropathy $(\mathrm{P}=0.007)$, whereas osteoprotegerin, osteocalcin, and 25-hydroxyvitamin D3 did not differ significantly among the stages of diabetic nephropathy. There was also no tendency for alterations in vascular calcification among the stages of nephropathy.

The results of simple regression analysis of variables associated with serum osteoprotegerin levels in the subjects are shown in Table 4 and Figure 2. Serum osteoprotegerin levels were positively correlated with age $(\mathrm{p}<0.0001)$, systolic blood pressure $(\mathrm{P}=0.03)$, and serum adiponectin levels $(\mathrm{P}=0.0008)$; and negatively correlated with $\mathrm{BMI}$ $(\mathrm{P}=0.045)$ and serum 25-hydroxyvitamin D3 $(\mathrm{P}=0.001)$.

\section{Discussion}

The results of the study demonstrate that vascular calcification is closely associated with serum osteoprotegerin levels in patients with diabetes [19], but is not linked to other bone-related humoral factors including osteocalcin, FGF23, and 25-hydroxyvitamin D3. Osteoprotegerin may directly affect osteoblastic changes of vascular smooth muscle cells and is not mediated through other factors or ions $[12,13]$. This differs from the effect of FGF23 on vascular calcification, since FGF23 regulates phosphate metabolism in kidney and promotes vascular calcification in association with phosphate [20]. In this study, we examined diabetic patients with mild or moderate renal impairment, including subjects with diabetic nephropathy of stages 1-4, since patients with advanced nephropathy may have vascular calcification without any interaction with cytokines [7].

FMD is a good indicator for vascular endothelial function and was found to be unrelated to serum osteoprotegerin or vascular calcification. These findings indicate that elevated serum osteoprotegerin may be involved in vascular calcification in patients with diabetes, independently of progression of diabetic nephropathy. However, because the study was performed as a cross-sectional observation, the finding of an association of serum osteoprotegerin and vascular calcification is limited and cannot suggest causality. However, osteoprotegerin may be clinically useful as a biochemical marker of vascular damage and overall burden of atherosclerotic disorders. In fact, serum osteoprotegerin is known to be associated with carotid and peripheral arterial disease in patients with type 2 diabetes [21] and is inversely associated with aortic distensibility [22]. Osteoprotegerin is also an independent predictor of coronary artery disease in asymptomatic type 2 diabetic patients with microalbuminuria [23] and is also predictive of the long-term outcome in patients with ST-elevation myocardial infarction treated with percutaneous coronary intervention [24]. 
Table 1 Presence or absence of cervical arterial calcification in quartiles based on serum osteoprotegerin, osteocalcin, FGF23, and 25-hydroxyvitamin D3 levels in 124 patients with type 2 diabetes

\begin{tabular}{|c|c|c|c|c|}
\hline & 1st quartile & 2nd quartile & 3rd quartile & 4th quartile \\
\hline Serum osteoprotegerin $(\mathrm{pg} / \mathrm{ml})^{a}$ & $<5.6$ & $5.6-8.4$ & $8.5-52.7$ & $52.8-9027$ \\
\hline No calcification, $n$ & $26^{*}$ & 25 & 19 & $16^{\#}$ \\
\hline Calcification, n & 5\# & 6 & 12 & $15^{*}$ \\
\hline Serum osteocalcin $(\mathrm{ng} / \mathrm{ml})^{b}$ & $0.77-0.82$ & $0.83-0.92$ & $0.93-1.53$ & $1.60-10.56$ \\
\hline No calcification, $\mathrm{n}$ & 24 & 18 & 21 & 23 \\
\hline Calcification, n & 7 & 13 & 10 & 8 \\
\hline$\overline{\text { Serum FGF23 }(\mathrm{pg} / \mathrm{ml})^{c}}$ & $10.0-22.7$ & $22.9-29.0$ & $29.7-40.7$ & $42.0-148.0$ \\
\hline No calcification, $\mathrm{n}$ & 24 & 20 & 19 & 23 \\
\hline Calcification, $\mathrm{n}$ & 7 & 11 & 12 & 8 \\
\hline${ }_{\text {Serum 25-hydroxyvitamin D3 }(\mathrm{nmol} / \mathrm{l}){ }^{d}}$ & $29.2-48.1$ & $48.6-77.3$ & $78.6-119.1$ & $121.1-239.3$ \\
\hline No calcification, $\mathrm{n}$ & 20 & 19 & 25 & 22 \\
\hline Calcification, n & 11 & 12 & 6 & 9 \\
\hline
\end{tabular}

${ }^{a} \mathrm{P}=0.015$ by chi-square test. *: Number of subjects significantly greater than other quartiles. ${ }^{\#}$ : Number of subjects significantly less than other quartiles.

b $\mathrm{P}=0.278$ by chi-square test.

c $\mathrm{P}=0.499$ by chi-square test.

${ }^{\mathrm{d}} \mathrm{P}=0.364$ by chi-square test.

Osteoprotegerin is a member of the TNF-related family [12] and exerts its major biological action through binding to RANKL as a soluble decoy receptor, with resulting inhibition of RANK stimulation of osteoclast differentiation and bone resorption $[13,25]$. RANKL and osteoprotegerin are expressed in osteoblasts, and the receptor RANK is expressed in osteoclasts cells [25]. In vascular beds, endothelial cells and vascular smooth muscle cells produce osteoprotegerin, but do not produce RANK and RANKL $[11,13,26,27]$. However, both RANKL and RANK expression have been detected in atherosclerotic lesions [28-30]. This may indicate that the RANK-RANKL interaction induces osteoclast formation and that osteoprotegerin blocks this interaction to reduce arterial calcification $[11,31,32]$. Therefore, vascular calcification linked to RANK-RANKL is independent of advanced vascular damage related to a long duration of diabetes, progression of diabetic microvascular complications, and abnormal metabolism of calcium or phosphate associated with FGF23, 25-hydroxyvitamin D3 and other factors. In the present study, we could not determine how the RANK/RANKL system participates in development of osteoclast differentiation in the vasculature in the non-advanced stage of diabetes mellitus. However, our findings suggest that vascular calcification may develop in patients with diabetes with high serum osteoprotegerin levels, even if

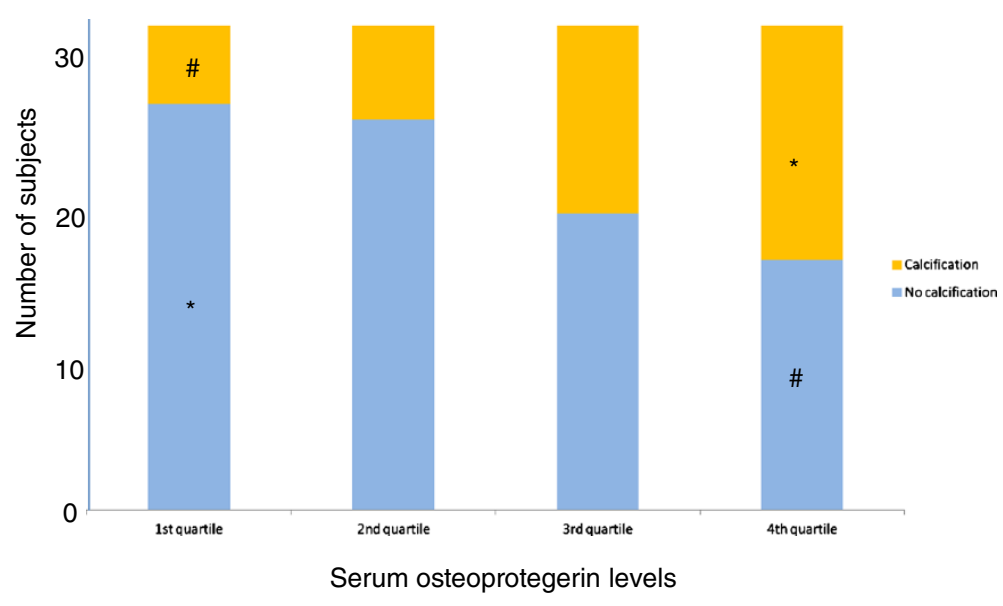

Figure 1 Presence or absence of cervical arterial calcification in quartiles based on serum osteoprotegerin levels in 124 patients with type 2 diabetes. $P=0.015$ by chi-square test. Serum osteoprotegerin levels in the 1 st, $2 \mathrm{nd}$, 3rd and 4th quartiles were $<5.6,5.6-8.4,8.5-52.7$, and $52.8-9027 \mathrm{pg} / \mathrm{ml}$, respectively. ${ }^{*}$ Number of subjects was significantly greater than in other quartiles. \# Number of subjects was significantly less than in other quartiles. 
Table 2 Clinical and laboratory data for 124 patients with type 2 diabetes divided into quartiles of serum osteoprotegerin levels (<5.6; 5.6-8.4; 8.5-52.7; and 52.8-9027 pg/ml)

\begin{tabular}{|c|c|c|c|c|c|}
\hline & 1st quartile & 2nd quartile & 3rd quartile & 4th quartile & $P$ value \\
\hline Subjects (male/female) & $31(25 / 6)$ & $31(20 / 11)$ & $31(23 / 8)$ & $31(20 / 11)$ & \\
\hline Age (years) & $61.0 \pm 1.2$ & $66.3 \pm 1.4^{*}$ & $65.9 \pm 1.5$ & $69.6 \pm 1.4^{* *}$ & 0.001 \\
\hline Height $(\mathrm{cm})$ & $165.3 \pm 1.4$ & $158.3 \pm 1.4^{* *}$ & $164.6 \pm 1.1^{\# \#}$ & $158.8 \pm 1.5^{* *, \$}$ & 0.001 \\
\hline Weight (kg) & $68.6 \pm 2.4$ & $59.6 \pm 1.7^{*}$ & $66.7 \pm 2.5$ & $60.0 \pm 1.7^{*}$ & 0.003 \\
\hline BMl & $24.9 \pm 0.7$ & $23.7 \pm 0.5$ & $24.5 \pm 0.7$ & $23.6 \pm 0.5$ & 0.366 \\
\hline Duration of diabetes mellitus (years) & $12.0 \pm 1.4$ & $16.9 \pm 1.6$ & $14.7 \pm 1.4$ & $15.2 \pm 1.4$ & 0.142 \\
\hline Systolic blood pressure (mmHg) & $127.0 \pm 2.6$ & $133.6 \pm 2.5$ & $136.1 \pm 4.6$ & $140.7 \pm 2.6^{*}$ & 0.029 \\
\hline Diastolic blood pressure (mmHg) & $74.7 \pm 1.5$ & $75.0 \pm 1.6$ & $74.9 \pm 1.7$ & $75.7 \pm 1.7$ & 0.975 \\
\hline FMD (\%) & $4.0 \pm 0.5$ & $4.4 \pm 0.4$ & $4.2 \pm 0.4$ & $3.0 \pm 0.7$ & 0.178 \\
\hline Mean IMT (mm) & $0.95 \pm 0.05$ & $1.07 \pm 0.06$ & $1.13 \pm 0.07$ & $1.04 \pm 0.09$ & 0.337 \\
\hline HbA1c (NGSP) (\%) & $8.0 \pm 0.4$ & $7.6 \pm 0.2$ & $7.9 \pm 0.2$ & $7.4 \pm 0.2$ & 0.371 \\
\hline Total cholesterol (mg/dl) & $192.1 \pm 7.7$ & $191.6 \pm 4.6$ & $188.1 \pm 6.4$ & $192.4 \pm 4.7$ & 0.953 \\
\hline Triglyceride (mg/dl) & $136.6 \pm 12.9$ & $129.7 \pm 12.6$ & $120.5 \pm 9.0$ & $137.1 \pm 10.8$ & 0.709 \\
\hline HDL-Cholesterol (mg/dl) & $47.8 \pm 2.3$ & $51.4 \pm 2.7$ & $55.2 \pm 2.3$ & $51.7 \pm 2.3$ & 0.210 \\
\hline LDL-Cholesterol (mg/dl) & $111.7 \pm 7.4$ & $113.8 \pm 4.3$ & $109.0 \pm 5.2$ & $113.0 \pm 5.2$ & 0.937 \\
\hline Creatinine (mg/dl) & $0.78 \pm 0.03$ & $0.79 \pm 0.03$ & $0.81 \pm 0.04$ & $0.83 \pm 0.05$ & 0.721 \\
\hline eGFR $\left(\mathrm{ml} / \mathrm{min} / 1.73 \mathrm{~m}^{2}\right)$ & $79.5 \pm 3.7$ & $70.0 \pm 3.0$ & $74.4 \pm 4.1$ & $69.2 \pm 3.4$ & 0.159 \\
\hline Albuminuria (mg/g creatinine) & $75.4 \pm 27.9$ & $146.8 \pm 37.6$ & $173.7 \pm 43.6$ & $117.4 \pm 53.6$ & 0.357 \\
\hline Adiponectin $(\mu \mathrm{g} / \mathrm{ml})$ & $5.8 \pm 0.7$ & $8.5 \pm 1.1$ & $9.0 \pm 1.6$ & $12.2 \pm 1.0^{* *}$ & 0.002 \\
\hline Osteocalcin (ng/ml) & $1.6 \pm 0.2$ & $1.7 \pm 0.4$ & $1.4 \pm 0.2$ & $1.9 \pm 0.3$ & 0.596 \\
\hline 25-hydroxyvitamin D3 (nmol/l) & $93.1 \pm 7.7$ & $103.4 \pm 7.3$ & $93.9 \pm 10.1$ & $61.9 \pm 5.6^{*, \# \#, \$}$ & 0.002 \\
\hline FGF23 (pg/ml) & $32.7 \pm 2.8$ & $31.3 \pm 3.1$ & $39.0 \pm 4.5$ & $34.8 \pm 2.2$ & 0.370 \\
\hline $\mathrm{Ca}(\mathrm{mg} / \mathrm{dl})$ & $9.3 \pm 0.05$ & $9.4 \pm 0.06$ & $9.4 \pm 0.07$ & $9.3 \pm 0.07$ & 0.499 \\
\hline iP (mg/dl) & $3.6 \pm 0.09$ & $3.6 \pm 0.09$ & $3.6 \pm 0.08$ & $3.5 \pm 0.08$ & 0.937 \\
\hline
\end{tabular}

Values are shown as mean \pm SE and were analyzed by ANOVA. eGFR: estimated glomerular filtration rate. ${ }^{*} \mathrm{P}<0.05$ vs. 1 st quartile. ${ }^{* *} \mathrm{P}<0.01$ vs. 1 st quartile. \# $P<0.05$ vs. 2 nd quartile. \#\# $P<0.01$ vs. 2 nd quartile. $\$ P<0.05$ vs. 3rd quartile. $\$ \$ P<0.01$ vs. 3rd quartile.

Table 3 Laboratory data for 124 patients with type 2 diabetes according to progression of diabetic nephropathy

\begin{tabular}{|c|c|c|c|c|c|}
\hline & Stage 1 & Stage 2 & Stage 3 & Stage 4 & $P$ value \\
\hline Subjects (male/female) & $59(42 / 17)$ & $40(24 / 16)$ & 19(17/2) & $6(5 / 1)$ & \\
\hline Serum creatinine $(\mathrm{mg} / \mathrm{dl})$ & $0.73 \pm 0.02$ & $0.81 \pm 0.03$ & $0.87 \pm 0.03^{*}$ & $1.2 \pm 0.10^{* *, \# \#, \$ \$}$ & $<0.001$ \\
\hline eGFR (ml/min) & $80.1 \pm 2.6$ & $69.3 \pm 2.9^{*}$ & $68.7 \pm 4.0$ & $46.5 \pm 3.2^{* *, \#}$ & $<0.001$ \\
\hline Albuminuria (mg/g creatinine) & $12.4 \pm 1.1$ & $95.0 \pm 10.7^{* *}$ & $483.8 \pm 63.6^{* *, \# \#}$ & $538.0 \pm 98.4^{* *, \# \#}$ & $<0.001$ \\
\hline Serum osteoprotegerin (pg/ml) & $183.8 \pm 117.5$ & $329.6 \pm 227.4$ & $168.1 \pm 87.2$ & $59.8 \pm 27.6$ & 0.876 \\
\hline Serum osteocalcin (ng/ml) & $1.58 \pm 0.21$ & $1.79 \pm 0.26$ & $1.35 \pm 0.32$ & $2.06 \pm 0.76$ & 0.696 \\
\hline Serum 25-hydroxyvitamin D3 (nmol/l) & $85.3 \pm 5.71$ & $86.2 \pm 6.52$ & $103.3 \pm 14.9$ & $81.1 \pm 18.8$ & 0.516 \\
\hline Serum FGF23 (pg/ml) & $32.6 \pm 1.83$ & $33.2 \pm 3.53$ & $36.1 \pm 3.57$ & $58.7 \pm 7.08^{* *}$ & 0.007 \\
\hline No calcification, $\mathrm{n}$ & 41 & 26 & 13 & 5 & \\
\hline Calcification, $\mathrm{n}$ & 18 & 14 & 4 & 1 & \\
\hline
\end{tabular}

Values are shown as mean $\pm \mathrm{SE}$ and were analyzed by ANOVA. ${ }^{*} \mathrm{P}<0.05$ vs. 1 st quartile. ${ }^{* *} \mathrm{P}<0.01$ vs. 1 st quartile. \# $\mathrm{P}<0.05$ vs. 2 nd quartile. \#\# $\mathrm{P}<0.01$ vs. 2 nd quartile. $\$ P<0.05$ vs. 3rd quartile. $\$ P<0.01$ vs. 3rd quartile. 
Table 4 Simple linear regression analysis of variables with possible associations with serum osteoprotegerin levels in patients with type 2 diabetes

\begin{tabular}{lcc}
\hline & P value & $\mathbf{r}$ \\
\hline Age & $<0.0001^{* *}$ & 0.367 \\
BMI & $0.045^{*}$ & -0.181 \\
Systolic blood pressure & $0.03^{*}$ & 0.195 \\
Diastolic blood pressure & 0.722 & -0.032 \\
Duration of diabetes mellitus (years) & 0.255 & 0.104 \\
HbA1c (NGSP) & 0.072 & -0.163 \\
Total-Cholesterol & 0.972 & -0.003 \\
Triglyceride & 0.927 & 0.008 \\
HDL-Cholesterol & 0.310 & 0.093 \\
LDL-Cholesterol & 0.809 & -0.022 \\
Creatinine & 0.878 & 0.014 \\
Ln (FGF23) & 0.373 & 0.081 \\
Ln (25-hydroxyvitamin D3) & $0.001^{* *}$ & -0.305 \\
Osteocalcin & 0.422 & 0.073 \\
Ln (FMD) & 0.294 & -0.096 \\
Mean IMT & 0.976 & 0.002 \\
Ln (Adiponectin) & $0.0008^{* *}$ & 0.339 \\
EPC & 0.330 & -0.134 \\
Ln Ca & 0.217 & -0.112 \\
iP & 0.983 & -0.002 \\
Ualb & 0.634 & 0.049 \\
CVRR & 0.362 & 0.087 \\
\hline & & \\
& &
\end{tabular}

microvascular and macrovascular disorders do not become manifest. The elevation of serum osteoprotegerin might be associated with underlying alterations in RANK/ RANKL interactions in the vascular wall.

Vascular calcification is common in patients with diabetes, and especially in those with diabetic nephropathy [8-10]. We have shown that coronary artery calcification is significantly increased in advanced diabetic nephropathy based on histology of intravascular ultrasound [7]. In such cases, abnormal calcium or phosphorus metabolism may also be involved in vascular calcification, in association with FGF23 or 25-hydroxyvitamin D3 [20,33]. As shown in Table 3, we found no relationship of vascular calcification or serum osteoprotegerin levels with diabetic nephropathy, and only 6 of the 124 subjects in the study had stage 4 diabetic nephropathy. Thus, most had no or mild nephropathy, making it evident that progression of vascular calcification is not simply associated with diabetic nephropathy.

BMI, systolic blood pressure, adiponectin and 25hydroxyvitamin D3 were among the factors correlated with serum osteoprotegerin in simple linear regression analysis. There was a highly significant positive correlation between

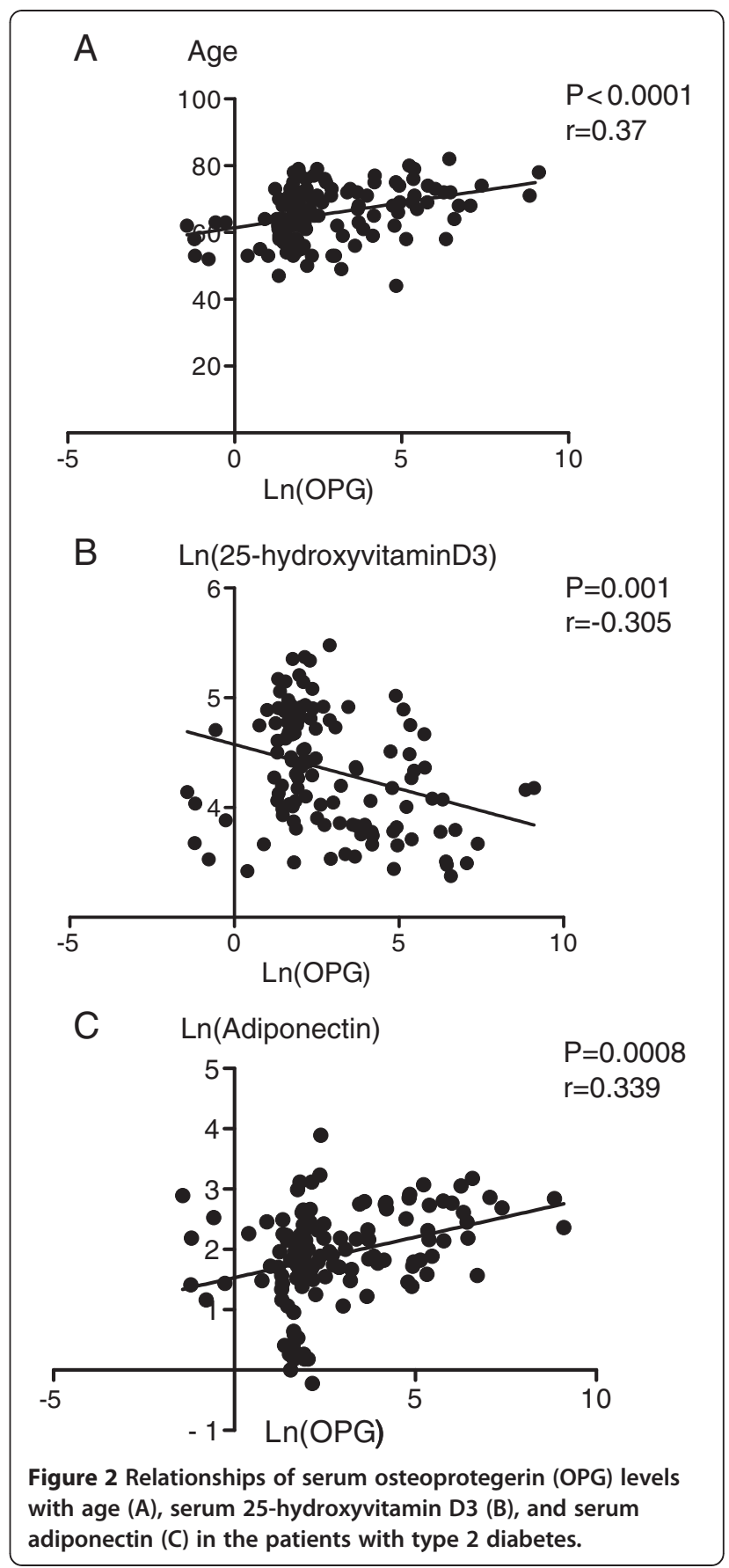

serum adiponectin and serum osteoprotegerin. In bone tissue, adiponectin stimulates RANKL in osteoclasts, thus inducing osteoclastogenesis [34]. In contrast, adiponectin inhibits osteoprotegerin in osteoblasts [34]. The positive correlation between serum adiponectin and osteoprotegerin [35] indicates that serum adiponectin may interact with osteoprotegerin for modulating osteoclast formation. Serum osteoprotegerin had a negative correlation with serum 25-hydroxyvitamin D3. Several studies have examined the effect of vitamin D3 on osteoprotegerin 
synthesis [36] and it has been shown that active $1 \alpha, 25-$ hydroxyvitamin D3 upregulates the level of RANKL, but downregulates osteoprotegerin expression in human periodontal ligament cells by accelerating degradation of osteoprotegerin mRNA and transrepressing the osteoprotegerin gene $[37,38]$. This indicates that active vitamin D3 promotes osteoclastogenesis. Similar interactions of osteoprotegerin with adiponectin and 25-hydroxyvitamin D3 may occur in vascular tissues, particularly with regard to the vascular calcification evaluated in this study.

\section{Conclusions}

Serum osteoprotegerin levels were closely associated with vascular calcification in patients with type 2 diabetes. Serum osteoprotegerin interacts with RANK/RANKL as a soluble decoy receptor to prevent osteoclast differentiation, and the elevation of serum osteoprotegerin might be linked to underlying alterations in RANK/RANKL interactions in the vascular wall. The levels of vascular calcification and serum osteoprotegerin were independent of progression of diabetic nephropathy. These findings indicate that elevated serum osteoprotegerin may be involved in vascular calcification in patients with type 2 diabetes mellitus.

\section{Abbreviations}

FGF 23: Fibroblast growth factor 23; OPG: Osteoprotegerin; TNF: Tumor necrosis factor; FMD: Flow-mediated dilatation; NMD: Nitroglycerinemediated dilatation; IMT: Intima-media thickness.

\section{Competing interests}

The authors declare that they have no competing interests.

\section{Authors' contributions}

$\mathrm{AA}, \mathrm{MM}$ and $\mathrm{SI}$ designed the study. AA, MM, TO, SJ and $\mathrm{NI}$ collected the data. AA, MM, TA, Al, MS, TS, MK and SI analyzed the data. AA, MM and SI wrote the first draft of the manuscript. All authors reviewed and edited the manuscript, and approved the final version of the manuscript for publication.

\section{Acknowledgements}

The study was supported by grants from the Ministry of Welfare, Labor and Health of Japan.

Received: 12 September 2012 Accepted: 31 October 2012 Published: 9 January 2013

\section{References}

1. Libby P, Ridker PM, Maseri A: Inflammation and atherosclerosis. Circulation 2002, 105:1135-1143.

2. Erkelens DW: Insulin resistance syndrome and type 2 diabetes mellitus. Am J Cardiol 2001, 88:38J-42J.

3. Gartner $V$, Eigentler TK: Pathogenesis of diabetic macro- and microangiopathy. Clin Nephrol 2008, 70:1-9.

4. Di Marzio D, Mohn A, Mokini ZH, Giannini C, Chiarelli F: Macroangiopathy in adults and children with diabetes: from molecular mechanisms to vascular damage (part 1). Horm Metab Res 2006, 38:691-705.

5. Sasaki A, Oikawa S, Toyota T: Microalbuminuria is closely related to diabetic macroangiopathy. Diabetes Res Clin Pract 1999, 44:35-40.

6. Yamagami K, Hosoi M, Yamamoto T, Fukumoto M, Yamakita T, Miyamoto M, Yoshioka K, Ishii T, Sato T, Tanaka S, Fujii S: Coronary arterial calcification is associated with albuminuria in type 2 diabetic patient. Diabetes Obes Metab 2005, 7:390-396.

7. Ogita M, Funayama H, Nakamura T, Sakakura K, Sugawara Y, Kubo N, Ako J, Ishikawa S, Momomura S: Plaque characterization of non-culprit lesions by virtual histology intravascular ultrasound in diabetic patients: impact of renal function. J Cardiol 2009, 54:59-65.

8. Ketteler M, Westenfeld R, Schlieper G, Brandenburg V: Pathogenesis of vascular calcification in dialysis patients. Clin Exp Nephrol 2005, 9:265-270.

9. Demer $L$, Tintut $Y$ : The bone-vascular axis in chronic kidney disease. Curr Opin Nephrol Hypertens 2010, 19:349-353.

10. Singh DK, Winocour P, Summerhayes B, Kaniyur S, Viljoen A, Sivakumar G, Farrington K: Prevalence and progression of peripheral vascular calcification in type 2 diabetes subjects with preserved kidney function. Diabetes Res Clin Pract 2012, 97:158-165.

11. Min H, Morony S, Sarosi I, Dunstan CR, Capparelli C, Scully S, Van G, Kaufman S, Kostenuik PJ, Lacey DL, Boyle WJ, Simonet WS: Osteoprotegerin reverses osteoporosis by inhibiting endosteal osteoclasts and prevents vascular calcification by blocking a process resembling osteoclastogenesis. J Exp Med 2000, 192:463-474.

12. Kong YY, Yoshida H, Sarosi I, Tan HL, Timms E, Capparelli C, Morony S, Oliveira-dos-Santos AJ, Van G, Itie A, Khoo W, Wakeham A, Dunstan CR, Lacey DL, Mak TW, Boyle WJ, Penninger JM: OPGL is a key regulator of osteoclastogenesis, lymphocyte development and lymph-node organogenesis. Nature 1999, 397:315-323.

13. Simonet WS, Lacey DL, Dunstan CR, Kelley M, Chang MS, Luthy R, Nguyen $\mathrm{HQ}$, Wooden S, Bennett L, Boone T, Shimamoto G, DeRose M, Elliott R, Colombero A, Tan HL, Trail G, Sullivan J, Davy E, Bucay N, Renshaw-Gegg L, Hughes TM, Hill D, Pattison W, Campbell P, Sander S, Van G, Tarpley J, Derby P, Lee R, Boyle WJ: Osteoprotegerin: a novel secreted protein involved in the regulation of bone density. Cell 1997, 89:309-319.

14. The Committee of the Japan Diabetes Society on the Diagnostic Criteria of Diabetes Mellitus: Report of the committee on the classification and diagnostic criteria of diabetes mellitus. J Diabetes Invest 2010, 1:212-228.

15. Celermajer DS, Sorensen KE, Gooch VM, Spiegelhalter DJ, Miller OI, Sullivan ID Lloyd JK, Deanfield JE: Non-invasive detection of endothelial dysfunction in children and adults at risk of atherosclerosis. Lancet 1992, 340:1111-1115.

16. Corretti MC, Anderson TJ, Benjamin EJ, Celermajer D, Charbonneau F, Creager MA, Deanfield J, Drexler H, Gerhard-Herman M, Herrington D, Vallance P, Vita J, Vogel R: Guidelines for the ultrasound assessment of endothelial-dependent flow-mediated vasodilation of the brachial artery: a report of the International Brachial Artery Reactivity Task Force. J Am Coll Cardiol 2002, 39:257-265.

17. Murata M, Tamemoto H, Saito T, Otani T, Jinbo S, Ikeda N, Kawakami M, Ishikawa S: Endoththelial Impairment and Bone Marrow-derived CD34+/ $133+$ Cells in Diabetic Subjects with Erectile Dysfunction. J Diabetes Invest 2012, 3:526-533.

18. Terminology and Diagnostic Criteria Committee, Japan Society of Ultrasonics in Medicine: Standard method for ultrasound evaluation of carotid artery lesions. Jpn J Med Ultrason 2009, 36:510-518. in Japanese.

19. Anand DV, Lahiri A, Lim E, Hopkins D, Corder R: The relationship between plasma osteoprotegerin levels and coronary artery calcification in uncomplicated type 2 diabetic subjects. J Am Coll Cardiol 2006, 47:1850-1857.

20. Mirza MA, Hansen T, Johansson L, Ahlstrom H, Larsson A, Lind L, Larsson TE: Relationship between circulating FGF23 and total body atherosclerosis in the community. Nephrol Dial Transplant 2009, 24:3125-3131.

21. Poulsen MK, Nybo M, Dahl J, Hosbond S, Poulsen TS, Johansen A, HoilundCarlsen PF, Beck-Nielsen H, Rasmussen LM, Henriksen JE: Plasma osteoprotegerin is related to carotid and peripheral arterial disease, but not to myocardial ischemia in type 2 diabetes mellitus. Cardiovasc Diabetol 2011, 10:76

22. Chen WJ, Rijzewijk $L$, van der Meer RW, Heymans MW, van Duinkerken E, Lubberink M, Lammertsma AA, Lamb HJ, de Roos A, Romijn JA, Smit JW, Bax JJ, Bjerre M, Frystyk J, Flyvbjerg A, Diamant M: Association of plasma osteoprotegerin and adiponectin with arterial function, cardiac function and metabolism in asymptomatic type 2 diabetic men. Cardiovasc Diabetol 2011, 10:67.

23. Reinhard H, Nybo M, Hansen PR, Wiinberg N, Kjaer A, Petersen CL, Winther $K$, Parving HH, Rasmussen LM, Rossing P, Jacobsen PK: Osteoprotegerin and coronary artery disease in type 2 diabetic patients with microalbuminuria. Cardiovasc Diabetol 2011, 10:70.

24. Pedersen S, Mogelvang R, Bjerre M, Frystyk J, Flyvbjerg A, Galatius S, Sorensen TB, Iversen A, Hvelplund A, Jensen JS: Osteoprotegerin predicts 
long-term outcome in patients with ST-segment elevation myocardial infarction treated with primary percutaneous coronary intervention. Cardiology 2012, 123:31-38.

25. Osako MK, Nakagami H, Koibuchi N, Shimizu H, Nakagami F, Koriyama H, Shimamura M, Miyake T, Rakugi H, Morishita R: Estrogen inhibits vascular calcification via vascular RANKL system: common mechanism of osteoporosis and vascular calcification. Circ Res 2010, 107:466-475.

26. Nadra I, Mason JC, Philippidis P, Florey O, Smythe CD, McCarthy GM, Landis RC, Haskard DO: Proinflammatory activation of macrophages by basic calcium phosphate crystals via protein kinase $C$ and MAP kinase pathways: a vicious cycle of inflammation and arterial calcification? Circ Res 2005, 96:1248-1256.

27. Hofbauer LC, Shui C, Riggs BL, Dunstan CR, Spelsberg TC, O'Brien T, Khosla S: Effects of immunosuppressants on receptor activator of NF-kappaB ligand and osteoprotegerin production by human osteoblastic and coronary artery smooth muscle cells. Biochem Biophys Res Commun 2001, 280:334-339.

28. Golledge J, McCann M, Mangan S, Lam A, Karan M: Osteoprotegerin and osteopontin are expressed at high concentrations within symptomatic carotid atherosclerosis. Stroke 2004, 35:1636-1641.

29. Schoppet M, Al-Fakhri N, Franke FE, Katz N, Barth PJ, Maisch B, Preissner KT, Hofbauer LC: Localization of osteoprotegerin, tumor necrosis factorrelated apoptosis-inducing ligand, and receptor activator of nuclear factor-kappaB ligand in Monckeberg's sclerosis and atherosclerosis. J Clin Endocrinol Metab 2004, 89:4104-4112.

30. Dhore CR, Cleutjens JP, Lutgens E, Cleutjens KB, Geusens PP, Kitslaar PJ, Tordoir JH, Spronk HM, Vermeer C, Daemen MJ: Differential expression of bone matrix regulatory proteins in human atherosclerotic plaques. Arterioscler Thromb Vasc Biol 2001, 21:1998-2003.

31. Morony S, Tintut Y, Zhang Z, Cattley RC, Van G, Dwyer D, Stolina M, Kostenuik PJ, Demer LL: Osteoprotegerin inhibits vascular calcification without affecting atherosclerosis in Idlr(-/-) mice. Circulation 2008, 117:411-420.

32. Kaden JJ, Bickelhaupt S, Grobholz R, Haase KK, Sarikoc A, Kilic R, Brueckmann M, Lang S, Zahn I, Vahl C, Hagl S, Dempfle CE, Borggrefe M: Receptor activator of nuclear factor kappaB ligand and osteoprotegerin regulate aortic valve calcification. J Mol Cell Cardiol 2004, 36:57-66.

33. Stubbs JR, Liu S, Tang W, Zhou J, Wang Y, Yao X, Quarles LD: Role of hyperphosphatemia and 1,25-dihydroxyvitamin $D$ in vascular calcification and mortality in fibroblastic growth factor 23 null mice. J Am Soc Nephrol 2007, 18:2116-2124.

34. Luo XH, Guo L, Xie H, Yuan LQ, Wu XP, Zhou HD, Liao EY: Adiponectin stimulates RANKL and inhibits OPG expression in human osteoblasts through the MAPK signaling pathway. J Bone Miner Res 2006, 21:1648-1656.

35. Gannage-Yared MH, Fares F, Semaan M, Khalife S, Jambart S: Circulating osteoprotegerin is correlated with lipid profile, insulin sensitivity, adiponectin and sex steroids in an ageing male population. Clin Endocrinol (Oxf) 2006, 64:652-658.

36. Notoya M, Otsuka E, Yamaguchi A, Hagiwara H: Runx-2 is not essential for the vitamin D-regulated expression of RANKL and osteoprotegerin in osteoblastic cells. Biochem Biophys Res Commun 2004, 324:655-660.

37. Kondo T, Kitazawa R, Maeda S, Kitazawa S: 1 alpha,25 dihydroxyvitamin D3 rapidly regulates the mouse osteoprotegerin gene through dual pathways. J Bone Miner Res 2004, 19:1411-1419.

38. Tang $X$, Meng H: Osteogenic induction and 1,25-dihydroxyvitamin D3 oppositely regulate the proliferation and expression of RANKL and the vitamin D receptor of human periodontal ligament cells. Arch Oral Biol 2009, 54:625-633.

doi:10.1186/1475-2840-12-11

Cite this article as: Aoki et al:: Association of serum osteoprotegerin with vascular calcification in patients with type 2 diabetes. Cardiovascular Diabetology 2013 12:11.

\section{Submit your next manuscript to BioMed Central and take full advantage of:}

- Convenient online submission

- Thorough peer review

- No space constraints or color figure charges

- Immediate publication on acceptance

- Inclusion in PubMed, CAS, Scopus and Google Scholar

- Research which is freely available for redistribution

Submit your manuscript at www.biomedcentral.com/submit
Ciomed Central 